\title{
Condensed Tannins
}

\section{DISTRIBUTION OF FLAVONOID COMPOUNDS IN THE HEARTWOODS AND BARKS OF SOME INTERRELATED WATTLES}

\author{
By D. G. ROUX, E. A. MAIHS and E. PAULUS \\ Leather Industries Research Institute, Rhodes University, Grahamstown, South Africa
}

(Received 22 July 1960)

The flavan-3-ols (-)-robinetinidol, (+)-catechin and $(+)$-gallocatechin occur in the bark (Roux, 1953; Roux \& Maihs, 1958, 1960a), whereas $(+)-7: 3^{\prime}: 4^{\prime}$ - trihydroxyflavan-3:4 - diol (Keppler, 1957), (+)-fustin, (-)-fisetinidol, fisetin and polymeric leuco-fisetinidin tannins (Roux \& Paulus, $1961 a, b)$ are prominent heartwood components of the commercially afforested black-wattle tree [Acacia mollissima, recently renamed $A$. mearnsii (cf. Brenan \& Melville, 1960)]. Of the four Acacia spp. introduced into South Africa from Austrajia for their tannin-rich bark, $A$. mearnsii is closely related to $A$. decurrens (green wattle) and to $A$. dealbata (silver wattle), all having feathery compound leaves of similar appearance. A. pycnantha (golden wattle) with leaves in the form of lanceolate phyllodes is known to be more distantly related to this group. In the present study the distribution of flavonoid compounds in the barks and heartwoods of these species is compared.

\section{EXPERIMENTAL AND RESULTS}

All melting points are uncorrected. Mixed melting points are performed on molecular mixtures (Roux \& Maihs, $1960 a$ ). Analyses of $\mathrm{C}$ and $\mathrm{H}$ were by Weiler and Strauss, Oxford. Infrared comparisons were by Dr J. R. Nunn, National Chemical Research Laboratory, C.S.I.R., Pretoria. A $2 \mathrm{dm}$. tube was used for optical rotations. Twodimensional chromatograms were run in water-saturated butan-2-ol for direction 1 and in $2 \%$ acetic acid for direction 2.

\section{Isolation, identification and estimation of heartwood components}

Acacia decurrens and Acacia dealbata. On two-dimensional chromatograms the methanol-soluble heartwood components of green and silver wattles show the same pattern of components as those present in black-wattle (A. mearnsii) heartwood extractives. Those heartwood components which have been isolated from black wattle, namely (+)-7:3' $: 4^{\prime}$-trihydroxyflavan-3:4-diol, (+)-fustin, $(-)$-fisetinidol and fisetin (Roux \& Paulus, 1961 $a, b$ ), were used to identify the corresponding components in $A$. decurrens and $A$. dealbata by means of two-dimensional

\footnotetext{
* Part 8: Roux \& Paulus (1961b).
}

paper chromatography. The addition of the abovementioned compounds caused increases in the concentration of the corresponding substances in each of the two extracts. Identity of the compounds was confirmed by colour reactions with toluene-p-sulphonic acid, ferric alum and bis-diazotized-benzidine spray reagents. The concurrence of spots and colour reactions were considered as sufficient proof of identity. Polymeric leuco-fisetinidin tannins occurred in each heartwood.

Acacia pycnantha. Golden wattle, although related to the above group, shows some divergent botanical characteristics. The pattern of heartwood components of $A$. pycnantha was almost identical with those of black, green and silver wattles but showed slight differences. Goldenwattle-heartwood components were accordingly isolated to ensure their identity.

Drillings (4.3 kg.) from the dry heartwood of goldenwattle trees from the Union Government Plantations at Eerste River, near Cape Town, were extracted with methanol in three successive extractions of $48 \mathrm{hr}$. duration each, to yield $213 \mathrm{~g}$. of solids. The solids were dissolved in hot ethanol $(500 \mathrm{ml}$.) and chloroform $(400 \mathrm{ml}$.) was added to precipitate tannins. The solubles $(130 \mathrm{~g}$.) were fractionated by solution in $400 \mathrm{ml}$. of ethyl acetate-thanol $(2: 1)$ followed by the addition of chloroform $(300 \mathrm{ml}$.) with shaking. The solids remaining after evaporation of the filtrate (83 g.) were resolved in a Craig machine by the method described by Roux \& Paulus (1961b). After 160 transfers fisetin (140-160), fustin (105-135), fisetinidol (105-125) and (+)-7:3':4' -trihydroxyflavan-3:4-diol (44-69) were located in the tubes indicated by means of twodimensional paper chromatography. The contents of the appropriate tubes were grouped together and the compounds isolated by separation on cellulose sheets as described by Roux \& Paulus (1961 a,b). Fisetin (20 mg.), fustin (2.3 g.), fisetinidol (150 mg.) and 7:3':4'-trihydroxyflavan-3:4-diol $(900 \mathrm{mg}$.) were obtained in a crystalline condition.

(a) Fisetin. The solids present in tubes 141-160 were boiled with $\mathrm{N}-\mathrm{H}_{2} \mathrm{SO}_{4}$ and the insoluble solids extracted with ether in a Soxhlet apparatus. The ether extractives were recrystallized from ethanol-water; m.p. and mixed m.p. with fisetin prepared from ( \pm )-fustin of Rhus glabra (Roux \& Paulus, 1961 a) $320^{\circ}$. $\lambda_{\max .} 252,320$ and $360 \mathrm{~m} \mu$ in ethanol.

(b) (+)-Fustin. The fustin was recrystallized from water, m.p. and mixed m.p. with (+)-fustin from $A$. mearnsii (Roux \& Paulus, 1961 a) 214-216 ${ }^{\circ} .[\alpha]_{-}^{28}+21 \cdot 5 \pm 2 \cdot 2^{\circ}$ in acetone-water $(1: 1)(c, 0.8)$. The tetra-acetyl derivative was prepared as before, m.p. and mixed m.p. with tetraacetyl-(+)-fustin $117-119^{\circ} .[\alpha]_{D}^{23}+22 \cdot 9 \pm 0 \cdot 1^{\circ}$ in tetra- 
chloroethane $(c, 1 \cdot 2)$. The low m.p. of the tetra-acetyl derivative compared with that of the racemate $\left(147-151^{\circ}\right)$, and the high optical rotations, indicate that optically pure (+)-fustin is present also in A. pycnantha heartwood.

(c) (-)-Fisetinidol. The fisetinidol was recrystallized from water (charcoal), m.p. and mixed m.p. with (-)-fisetinidol from A. mearnsii (Roux \& Paulus, 1961b) 212$214^{\circ}$. $[\alpha]_{b}^{22}-4 \cdot 9 \pm 0 \cdot 3^{\circ}$ in acetone-water $(1: 1)(c, 0 \cdot 8)$. In $2 \%$ acetic acid on Whatman no. 1 paper the $R_{r}(0.48)$ of the fisetinidol differed from that $(0 \cdot 43)$ of synthetic $(+)$ fisetinidol (Weinges, 1958), but was identical with the $R_{F}$ $(0 \cdot 48)$ of synthetic (-)-fisetinidol (Roux \& Paulus, 1961 b). Paper chromatography showed that only the optically pure $(-)$-form is present.

(d) (+)-7:3':4'-Trihydroxyflavan-3:4-diol. The flavan3:4-diol was also isolated by running $24 \mathrm{~g}$. of the soluble fraction (after chloroform precipitation) on 60 sheets of Whatman no. 3 paper in $2 \%$ acetic acid and cutting the band located with the toluene-p-sulphonic acid spray (Roux \& Evelyn, 1958b). Yield, 0.7 g. The flavan-3:4-diol was recrystallized from water, m.p. and mixed m.p. with (+)-mollisacacidin (Keppler, 1957; Clark-Lewis \& Roux, 1959) $129^{\circ} .[\alpha]_{D}^{21}+30 \cdot 7 \pm 0 \cdot 8^{\circ}$ in acetone-water $(1: 1)(c, 1 \cdot 0)$. The $R_{F}(0.54)$ in $2 \%$ acetic acid on Whatman no. 1 paper was identical with that of $(+)-7: 3^{\prime}: 4^{\prime}$-trihydroxyflavan-3:4diol $(0.54)$ from $A$. mearnsii (Roux \& Maihs, 1960b), but differed from the $R_{p}(0.48)$ of the (-)-enantiomer from S. quebracho-colorado. Infrared-absorption curves of the flavan-3:4-diols from $A$. pycnantha and $A$. mearnsii were superimposable over the range $2 \cdot 5-15 \mu$.

(e) Gallic acid. A compound present in tubes 64-79 of the Craig machine was isolated by separation on cellulose sheets (30 mg.). It gave a blue colour with ferric alum spray, and a purple colour with the borate buffer ( $\mathrm{pH} 7 \cdot 7$ )methyl red spray (Kalbe, 1954), indicating that the substance contained a pyrogallol grouping and was acidic. The compound was shown to be gallic acid by m.p. and mixed m.p. with authentic gallic acid $250^{\circ}$.

\section{Estimation of flavonoid compounds in wattle heartwoods}

Cross-sections of each of the heartwoods of black, green, silver and golden wattles were drilled out and the drillings were extracted with methanol (five extractions of $24 \mathrm{hr}$. duration each at room temperature). The tree samples were of different ages [black (10 years), green (9 years), silver (10 years) and golden (about 30 years)] and the sampling height above the ground is unknown.The concentration of components in the methanol extract was estimated by the paper-chromatographic-densitometric method, ammoniacal silver nitrate being used as spray reagent (Roux \& Maihs, $1960 a, b$ ). Estimated percentages of different components in the four heartwoods are shown in Table 1.

\section{Isolation, identification and estimation of bark components}

The barks of the different Acacia species show no significant change in the composition of catechin components with increasing age, although the proportion of carbohydrate 'non-tannins' is known to decrease progressively. The average molecular weight of the tannins in the youngest strippable bark of $A$. mearnsii does not, for example, differ significantly from those in mature barks of the same tree (Evelyn, 1956). For this work 'mature' barks from the bases of 7-10-year-old trees were selected, with the exception of $A$. pycnantha, where the specimens were over 30 years old.

Acacia decurrens. Green-wattle-bark extract is apparently identical with black wattle in the composition of catechin components, differing only in the proportions of catechins present (Table 2). (-)-Robinetinidol, (+)-catechin and (+)-gallocatechin were shown to be present in green-wattle bark extractives with the chromatographic method described for heartwood components, and reference substances were obtained from black-wattle bark (Roux \& Maihs, $1960 a$ ).

Acacia dealbata. Two-dimensional chromatograms of silver-wattle-bark extractives sprayed with bis-diazotized benzidine reagent showed the presence of $(-)$-robinetinidol (yellow), (+)-catechin (ochre), (+)-gallocatechin (ochre) and of a fourth substance also giving an ochre coloration. From its position on the chromatograms the latter was suspected to be (-)-epicatechin. Out of ten barks, from different trees examined, three showed the suspected (-)-epicatechin in relatively high concentration. The concentration of the other catechins was relatively constant (Table 3). The catechins were separated and identified as follows.

A portion $(470 \mathrm{~g}$.$) of the ethyl acetate extractives$ $(560 \mathrm{~g}$.$) of dry powdered silver-wattle bark [low in (-)-$ epicatechin content] was soluble on re-solution in commercial ethyl acetate. Tannins present in the soluble

\section{Table 1. Estimation of flavonoid compounds in wattle heartwoods}

Concentration in methanol extractives* $(\%)$

(+) $-7: 3^{\prime}: 4^{\prime}-$ Tri-

\section{Sample}

Black wattle (A. mearnsii)

Green wattle $(A$. decurrens)

Silver wattle $\ddagger$ ( $A$. dealbata)

Golden wattle ( $A$. pycnantha)

hydroxyflavan-
hy-

3:4-diol
$2 \cdot 0$
$1 \cdot 6$
$0 \cdot 9$
$2 \cdot 3$

$\begin{array}{cc}(+) \text {-Fustin } & (-) \text {-Fisetinidol } \dagger \\ 5 \cdot 1 & 0 \cdot 6 \\ 2 \cdot 1 & \text { Trace } \\ 2 \cdot 1 & 0 \cdot 4 \\ 7 \cdot 2 & 0 \cdot 6\end{array}$

Fisetin
$\mathbf{2} \cdot 0$
$0 \cdot 8$
$\mathbf{0} \cdot 8$
$\mathbf{4} \cdot 0$

Gallic acid

Absent
Absent
Absent
0.2

* Obtained from air-dried samples 2-3 years old. Compare concentrations in freshly cut $A$. mearnsii from the Grahamstown district (Roux \& Paulus, $1960 a, b$ ).

$\dagger$ Percentages obtained by visual estimation; others were obtained by densitometric measurement.

† These samples contained abnormally high proportions of carbohydrate material, hence the reduced percentages of flavonoid compounds. 
fraction were precipitated in batches with samples (10 g.) dissolved in $100 \mathrm{ml}$. of ethyl acetate-methanol $(20: 1)$ and adding $100 \mathrm{ml}$. of chloroform. The low-molecular-weight fraction remaining in solution after removal of the precipitated tannins was $10 \%$ of the starting material.

The enriched catechin fraction (56 g.) was streaked on to 140 sheets of Whatman no. 3 chromatographic paper $(0.4 \mathrm{~g}$./sheet) and the sheets were developed by upward migration in $2 \%$ acetic acid as described by Roux \& Evelyn $(1958 a, b)$. Bands corresponding to $(-)$-robinetinidol $\left(R_{F} 0.54\right),(+)$-catechin $\left(R_{F} 0.48\right)$ and (-)-epicatechin $\left(R_{F} 0.44\right)$ were located by the bis-diazotized benzidine reagent. The bands were cut and eluted with $70 \%$ ethanol (Nordström \& Swain, 1953), yielding 0.4, 5.0 and $2 \cdot 2 \mathrm{~g}$. of solids respectively in the eluents. The solids from each band were streaked on prewashed (with water) sheets of Whatman no. 3 paper $(200 \mathrm{mg}$./sheet dissolved in $5 \mathrm{ml}$. of methanol), and the chromatograms were developed downwards in butan-1-ol-acetic acid-water $(6: 1: 2)$. Bands were located, cut and eluted as before. From the eluents (+)-catechin (1.0 g.) crystallized with ease, but ( - )-robinetinidol (40 mg.) and (-)-epicatechin (200 mg.) were run again in the partitioning mixture before crystallizing. (+)-Gallocatechin (18 mg.) was obtained from the same band $\left(R_{F} 0.48\right.$ in $2 \%$ acetic acid) in which $(+)$ - catechin was present in the initial fractionation, and crystallized after seeding with $(+)$-gallocatechin crystals from golden wattle.

(a) (-)-Robinetinidol. Robinetinidol from silver wattle was recrystallized from water, m.p. and mixed m.p. with (-)-robinetinidol (m.p. $205^{\circ}$ ) from black wattle $202^{\circ}$. $\lambda_{\text {max. }}$ in ethanol 202 and $282 \mathrm{~m} \mu$ ( $\epsilon$ at $282 \mathrm{~m} \mu$ 3636) (Found: C, 56.7; H, 5.5; loss at $110^{\circ}, 8.4$. Calc. for $\mathrm{C}_{15} \mathrm{H}_{14} \mathrm{O}_{6}, 1 \cdot 5 \mathrm{H}_{2} \mathrm{O}: \mathrm{C}, 56 \cdot 8 ; \mathrm{H}, 5 \cdot 4 ; \mathrm{H}_{2} \mathrm{O}, 8 \cdot 5 \%$ ). The solution in acetone-water $(1: 1)$ was not sufficiently clear to permit measurements of optical rotation, but the robinetinidol migrated to the same position as (-)-robinetinidol on twoway chromatograms with a combination of solvent systems which separate all the stereoisomers of catechins (Roberts \& Wood, 1953).

(b) (+)-Catechin. The substance was recrystallized from water, m.p. and mixed m.p. with $(+)$-catechin from Uncaria gambir $175-176^{\circ} . \lambda_{\max }$. in ethanol 207.5 and $281 \mathrm{~m} \mu$ ( $\epsilon$ at $281 \mathrm{~m} \mu 3830$ ) (Found : C, 59.2 ; H, 5.6 ; loss at $110^{\circ}$, 3.4. Calc. for $\mathrm{C}_{15} \mathrm{H}_{14} \mathrm{O}_{6}, \mathrm{H}_{2} \mathrm{O}: \mathrm{C}, 58 \cdot 4 ; \mathrm{H}, 5 \cdot 2 ; \mathrm{H}_{2} \mathrm{O}$, $5 \cdot 1 \%) .[\alpha]_{\mathrm{D}}^{21}+17 \cdot 0 \pm 0 \cdot 1^{\circ}$ in acetone-water $(1: 1)(c, 2 \cdot 3)$. The acetyl derivative, m.p. and mixed m.p. with authentic penta-acetyl- $(+)$-catechin, $\quad 130^{\circ} . \quad[\alpha]_{D}^{21}+29 \cdot 4 \pm 0 \cdot 4^{\circ}$ in acetone $(c, 0.9)$.

(c) (-)-epiCatechin. The substance was recrystallized from water, m.p. and mixed m.p. with (-)-epicatechin from cocoa beans (Forsyth, 1955) $235^{\circ}$ (decomp.). $\lambda_{\max .}$ in

Table 2. Estimation of catechins in the bark extracts of different specimens of black and green wattles and of black $\times$ green wattle hybrids

Concentration (\%) in methanol extractives is given as a mean with the range in parentheses and number of samples as a superior figure.

\section{Sample}

Black wattle (A. mearnsii) on shale

Black wattle (A. mearnsii) on dolerite

Black $\times$ green wattle hybrids $\dagger$

Green wattle ( $A$. decurrens) on shale

$(-)$-Robinetinidol
$0.23(0.2-0.3)^{10}$
$0.18(0.1-0.25)^{5}$
$0.17(0.1-0.25)^{5}$
$0.12(0.1-0.15)^{5}$

(+)-Catechin $0.57(0.5-0.65)^{10}$

$0.51(0.45-0.6)^{5}$

$1 \cdot 15(0 \cdot 85-1 \cdot 3)^{5}$

$1 \cdot 22(1 \cdot 1-1 \cdot 5)^{5}$
(+)-Gallocatechin* $0.32(0.25-0.4)^{10}$ $0.42(0.35-0.5)^{5}$ $0.48(0.25-0.6)^{5}$ $0.44(0.4-0.5)^{5}$

* Estimation by visual comparison.

$\dagger$ Artificial hybrids produced by the Wattle Research Institute, Pietermaritzburg, Natal, during plant-breeding and genetic studies.

Table 3. Estimation of catechins in the bark extracts of black, green, silver and golden wattles -, Absent.

Concentration in methanol extractives (\%)

\begin{tabular}{|c|c|c|c|c|c|c|c|}
\hline \multirow[b]{2}{*}{ Species } & & & & & & & \\
\hline & $\begin{array}{l}\text { (-)-Robin- } \\
\text { etinidol }\end{array}$ & $(+)$-Catechin & $\begin{array}{l}(-)-e p i- \\
\text { Catechin }\end{array}$ & $\begin{array}{c}(-)-\varphi p i- \\
\text { Catechin } \\
\text { gallate }\end{array}$ & $\begin{array}{l}\text { (+)-Gallo- } \\
\text { catechin }\end{array}$ & $\begin{array}{l}\text { (-)-epi- } \\
\text { Gallo- } \\
\text { catechin }\end{array}$ & $\begin{array}{c}\text { (-)-epi- } \\
\text { Gallo- } \\
\text { catechin } \\
\text { gallate }\end{array}$ \\
\hline $\begin{array}{l}\text { Black wattle* }(A \text {. } \\
\text { mearnsii) (Natal) }\end{array}$ & 0.3 & 0.2 & - & - & $0 \cdot 15$ & - & - \\
\hline $\begin{array}{l}\text { Black wattle* } \\
\text { (Grahamstown) }\end{array}$ & $0 \cdot 3$ & 1.0 & - & - & 0.4 & - & - \\
\hline $\begin{array}{l}\text { Green wattle } \\
(\text { A. decurrens })\end{array}$ & $0 \cdot 35$ & 0.95 & - & - & 0.35 & - & - \\
\hline $\begin{array}{c}\text { Silver wattle } \dagger \\
(A \text {. dealbata })\end{array}$ & Trace & $0 \cdot 6$ & $0 \cdot 1$ & - & 0.05 & Trace & - \\
\hline $\begin{array}{l}\text { Silver wattle } \dagger \\
\text { Golden wattle }\end{array}$ & $\begin{array}{l}0 \cdot 1 \\
0 \cdot 05\end{array}$ & $\begin{array}{l}0 \cdot 6 \\
0.65\end{array}$ & $\begin{array}{l}0.5 \\
0.45\end{array}$ & $\overline{0.5}$ & $\begin{array}{l}\text { Trace } \\
0.4\end{array}$ & $\begin{array}{l}\text { Trace } \\
0 \cdot 2\end{array}$ & $\overline{0.3}$ \\
\hline
\end{tabular}

(A. pycnantha)

* Black wattle from Natal is that used for commercial afforestation; samples from the Albany district (Grahamstown) are of unknown botanical origin but possess all the botanical characteristics of $A$. mearnsii.

$\dagger$ Silver wattles have barks both 'rich' and 'poor' in (-)-epicatechin. In those examined the latter type predominates. 
ethanol 207.5 and $281 \mathrm{~m} \mu$ ( $\epsilon$ at $281 \mathrm{~m} \mu$ 3886) (Found: C, $58 \cdot 9 ; \mathrm{H}, 5 \cdot 1$; loss at $110^{\circ}, 4 \cdot 6$. Calc. for $\mathrm{C}_{15} \mathrm{H}_{14} \mathrm{O}_{6}, \mathrm{H}_{2} \mathrm{O}$ : C, $\left.58 \cdot 4 ; \mathrm{H}, 5 \cdot 2 ; \mathrm{H}_{2} \mathrm{O}, 5 \cdot 1 \%\right) \cdot[\alpha]_{\mathrm{D}}^{21}-57 \cdot 1 \pm 0 \cdot 7^{\circ}$ in acetonewater $(\mathbf{1}: \mathbf{1})(c, 0 \cdot 6)$.

(d) (+)-Gallocatechin. The crystals darkened rapidly after recrystallization from water, m.p. and mixed m.p. with (+)-gallocatechin from dried green-tea leaves (Bradfield, Penney \& Wright, 1947; Bradfield \& Penney, 1948) $185^{\circ} . \lambda_{\max }$ in ethanol $270.5 \mathrm{~m} \mu(\epsilon 1760)$. Gallocatechin from silver wattle gave an ochre colour with bis-diazotized benzidine spray and a blue with ferric alum spray. The gallocatechin also migrates to the identical position with ( +)-gallocatechin on two-way chromatograms with solvent systems which separate catechin stereoisomers (Roberts \& Wood, 1953).

(e) (-)-epiGallocatechin. Ethyl acetate-soluble silverwattle-bark extracts from which tannins were partly removed by passing the aqueous solution through a column of hide powder showed the presence of traces of a substance migrating to the same position on two-way chromatograms (Roberts \& Wood, 1953) and giving the same colour reactions as ( -)-epigallocatechin.

Acacia pycnantha. A two-dimensional chromatogram of the ethyl acetate extract of golden-wattle bark showed the presence of a number of phloroglucinol-containing substances [amber colour with bis-diazotized benzidine (Roux $\&$ Maihs, 1960b)] in a pattern identical with that found in the extractives of dried green tea. The known catechins of dried green tea (Bradfield et al. 1947 ; Bradfield \& Penney, 1948; Bradfield \& Bate-Smith, 1950; Roberts \& Wood, $1951,1953)$ were isolated for comparison by the same methods described below for golden wattle, but without preliminary chloroform precipitation.

The ethyl acetate extract ( $230 \mathrm{~g}$.) of golden-wattle bark was redissolved in ethyl acetate and the tannins were precipitated with chloroform as for silver wattle. The resulting soluble low-molecular-weight fraction ( $32 \mathrm{~g}$.) was separated on 80 sheets of Whatman no. 1 paper with $2 \%$ acetic acid. On the dried sheets the bands were located by spraying test strips with the benzidine reagent and by ultraviolet light. Bands corresponding to $R_{F}$ values $0.56(0.4 \mathrm{~g}$.), 0.50 $(2.0$ g.), $0.42(2.2$ g.), $0.35(2.8$ g.) and $0.29(4.3$ g.) were cut and eluted in $70 \%$ ethanol to give the weights of solids indicated. The fractions contained the following main components: $R_{F} 0.56$ [(-)-robinetinidol]; $R_{F} 0.50[(+)$-catechin, gallic acid, (+)-gallocatechin]; $R_{F} 0.42[(-)$-epicatechin, (-)-epicatechin gallate, (-)-epigallocatechin]; $R_{F} \quad \mathbf{0 . 3 5}$ [(-)-epicatechin gallate, (-)-epigallocatechin gallate, (-)-epigallocatechin]; $R_{F} \quad 0.29$ [(-)-epigallocatechin gallate]. Each band was separated on washed paper sheets in a partitioning mixture as described for silver wattle. The following substances were isolated after recrystallization from water, and where necessary compared with similar substances obtained from tea by identical methods, and also from other sources.

(a) (-)-Robinetinidol. This compound formed less than $20 \%$ of the fraction, $R_{F} 0.56$ in $2 \%$ acetic acid. Yield, $32 \mathrm{mg}$. M.p. and mixed m.p. with (-)-robinetinidol 203$204^{\circ}$. $\lambda_{\max }$ in ethanol $282 \mathrm{~m} \mu(\epsilon$ 3944). The compound gives the same colour reactions (blue with ferric alum, and yellow with bis-diazotized benzidine spray reagents) as ( - )-robinetinidol, and their optical identity was shown by their concurrence on two-way chromatograms with the solvent systems below: $R_{F} \mathbf{0 . 7 8}$ in butan-1-ol-acetic acid- water (6:1:2) (solvent 1 ) and $R_{F} 0.42$ in $2 \%$ acetic acid (solvent 2) on Whatman no. 1 paper.

(b) (+)-Catechin. Yield, $700 \mathrm{mg} . R_{p} \mathbf{0 \cdot 7 6}$ (solvent 1) and $R_{F} 0.35$ (solvent 2). M.p. and mixed m.p. with $(+)$-catechin from Uncaria gambir $177^{\circ} .[\alpha]_{\mathrm{D}}^{21}+16 \cdot 8 \pm 0 \cdot 4^{\circ}$ in acetonewater $(1: 1)(c .2 \cdot 3) . \quad \lambda_{\max }$ in ethanol $281 \mathrm{~m} \mu(\epsilon$ 4080) (Found: C, 58.3; H, 5.4. Calc. for $\mathrm{C}_{15} \mathrm{H}_{14} \mathrm{O}_{6}, \mathrm{H}_{2} \mathrm{O}: \mathrm{C}, 58 \cdot 4$; $\mathrm{H}, 5 \cdot 2 \%)$. The acetate, m.p. and mixed m.p. with pentaacetyl- $(+)$-catechin $131^{\circ} .[\alpha]_{\mathrm{p}}^{21}+28 \cdot 4 \pm 0 \cdot 4^{\circ}$ in acetone $(c$, $0 \cdot 8)$.

(c) (-)-epiCatechin. Yield, $80 \mathrm{mg} . R_{F} 0 \cdot 62$ (solvent 1) and $R_{F}, 0.30$ (solvent 2). M.p. and mixed m.p. with (-)epicatechin from cocoa beans (Forsyth, 1955) $236^{\circ}$ (decomp.). $[\alpha]_{\mathrm{D}}^{20}-63.2 \pm 0.5^{\circ}$ in ethanol $(c, 0.4)$, and $-57 \cdot 4 \pm 0.5^{\circ}$ in acetone-water $(1: 1)(c, 0.6) . \quad \lambda_{\max }$ in ethanol $280 \mathrm{~m} \mu(\epsilon 4008)$ (Found: C, 56.4 ; H, 5•2. Calc. for $\mathrm{C}_{15} \mathrm{H}_{14} \mathrm{O}_{6}, 1 \cdot 5 \mathrm{H}_{2} \mathrm{O}: \mathrm{C}, 56 \cdot 8 ; \mathrm{H}, 5.4 \%$. Loss at $110^{\circ}$ not determined). Evaporation of aqueous solutions of (-)-epicatechin during purification always resulted in some transformation into (-)-catechin, an epimerization reaction which occurs readily (Roberts \& Wood, 1951, 1953).

(d) (-)-epiCatechin gallate. Yield, $135 \mathrm{mg}$. Initially this substance [and also (-)-epigallocatechin gallate] crystallized with great difficulty, but crystallization was induced by slow evaporation of the solvent in a desiccator over $\mathrm{CaCl}_{2}$ at room temperature. $R_{F} 0.90$ (solvent 1) and $R_{F}$ 0.25 (solvent 2). M.p. 257-258 ${ }^{\circ}$, and mixed m.p. with (-)epicatechin gallate (m.p. 254-255 $)$ from dried green-tea leaves $254-255^{\circ} .[\alpha]_{\mathrm{D}}^{21}-181 \cdot 0 \pm 1 \cdot 0^{\circ}$ in ethanol $(c, 0 \cdot 3)$, and $-222 \cdot 2 \pm 3 \cdot 0^{\circ}$ in acetone-water $(1: 1)(c, 0 \cdot 3) . \lambda_{\max }$ in ethanol $280 \mathrm{~m} \mu$ ( $\epsilon$ 13570) (Found: C, 59.0; H, 4.3; loss at $110^{\circ}, 2 \cdot 1$. Calc. for $\mathrm{C}_{22} \mathrm{H}_{18} \mathrm{O}_{10}, 0 \cdot 5 \mathrm{H}_{2} \mathrm{O}: \mathrm{C}, 58 \cdot 5 ; \mathrm{H}, 4 \cdot 2$; $\mathrm{H}_{2} \mathrm{O}, 2.0 \%$ ). The acetate (118 mg.) was formed from the epicatechin gallate $(110 \mathrm{mg}$.) by acetylation with the acetic anhydride-pyridine mixture, and the product recrystallized from $90 \%$ acetic acid, m.p. $118 \cdot 5^{\circ} \cdot[\alpha]_{D}^{21}-86 \cdot 7 \pm$ $0.3^{\circ}$ in acetone $(c, 0.76)$.

(e) (+)-Gallocatechin. Yield, $410 \mathrm{mg} . R_{F} \mathbf{0 . 5 2}$ (solvent 1 ) and $R_{F} 0.31$ (solvent 2). M.p. 182-183 ${ }^{\circ}$, and mixed m.p. with (+)-gallocatechin from Casuarina equisetifolia (Roux, 1957) $181-182^{\circ} .[\alpha]_{\mathrm{D}}^{21}+10 \cdot 1 \pm 0 \cdot 3^{\circ}$ in acetone-water $(1: 1)$ $(c, 1 \cdot 3) . \lambda_{\text {max. }}$ in ethanol $270.5 \mathrm{~m} \mu(\epsilon 1,820)$ (Found: $\mathrm{C}$, $52 \cdot 2$; $\mathrm{H}, 4 \cdot 8$; loss at $110^{\circ}, 8 \cdot 0$. Calc. for $\mathrm{C}_{15} \mathrm{H}_{14} \mathrm{O}_{7}, 1 \cdot 5 \mathrm{H}_{2} \mathrm{O}$ : C, $52.6 ; \mathrm{H}, 5.3 ; \mathrm{H}_{2} \mathrm{O}, 10.5 \%$ ). The gallocatechin (120 mg.) was acetylated as described above to give an acetate (116 mg.) recrystallized from ethanol, m.p. $141^{\circ} \cdot[\alpha]_{D}^{21}+$ $28 \cdot 6 \pm 0 \cdot 4^{\circ}$ in acetone $(c, 0 \cdot 6)$.

$(f)$ ( -)-epiGallocatechin. Yield, $55 \mathrm{mg} . R_{F} 0.45$ (solvent 1) and $R_{F} 0.24$ (solvent 2). M.p. $215^{\circ}$, and mixed m.p. with (-)-epigallocatechin (m.p. 214-215 ${ }^{\circ}$ from tea $215^{\circ}$. $[\alpha]_{D}^{21}-58.7 \pm 0.5^{\circ}$ in ethanol $(c, 0.5)$, and $-65.0 \pm 1.4^{\circ}$ in acetone-water $(1: 1)(c, 0.5) . \quad \lambda_{\max }$ in ethanol $270.5 \mathrm{~m} \mu$ $\left(\epsilon\right.$ 1786) (Found: $\mathrm{C}, 53.8 ; \mathrm{H}, 5.0$; loss at $110^{\circ}, 7 \cdot 5$. Calc. for $\mathrm{C}_{15} \mathrm{H}_{14} \mathrm{O}_{7}, 1 \cdot 5 \mathrm{H}_{2} \mathrm{O}: \mathrm{C}, 54 \cdot 1 ; \mathrm{H}, 5 \cdot 1 ; \mathrm{H}_{2} \mathrm{O}, 8.1 \%$ ). The epigallocatechin from green tea $(118 \mathrm{mg}$.) was acetylated to give an acetate $(128 \mathrm{mg}$.), which was recrystallized from ethanol, m.p. $195^{\circ} .[\alpha]_{\mathrm{D}}^{21}-16 \cdot 4 \pm 0 \cdot 3^{\circ}$ in acetone $(c, 0 \cdot 7)$.

(g) (-)-epiGallocatechin gallate. Yield, $150 \mathrm{mg} . R_{F} 0.72$ (solvent 1) and $R_{F} 0.22$ (solvent 2). M.p. $220^{\circ}$, and mixed m.p. with (-)-epigallocatechin gallate (m.p. $220^{\circ}$ ) from tea $219-220^{\circ}$ with decomposition at $221^{\circ}$. $[\alpha]_{D}^{21}-177 \pm 0 \cdot 7^{\circ}$ in ethanol $(c, 0.3)$ and $-220.5 \pm 1.6^{\circ}$ in acetone-water $(1: 1)$ $(c, 0 \cdot 2) . \lambda_{\max }$ in ethanol 276 and $279 \cdot 5 \mathrm{~m} \mu(\epsilon 9930$ and 9950 respectively) (Found: C, 55.2; H, 4.8; loss at $110^{\circ}, 4.9$. 
Calc. for $\mathrm{C}_{22} \mathrm{H}_{18} \mathrm{O}_{11}, \mathrm{H}_{2} \mathrm{O}: \mathrm{C}, 55.5 ; \mathrm{H}, 4 \cdot 2 ; \mathrm{H}_{2} \mathrm{O}, 3.8 \%$ ). The epigallocatechin gallate (118 mg.) was acetylated as described above and the acetate $(95 \mathrm{mg}$ ) recrystallized from $90 \%$ acetic acid, m.p. $119 \cdot 5-120 \cdot 5^{\circ}$.

(h) Gallic acid. Yield, $150 \mathrm{mg}$. M.p. and mixed m.p. with authentic gallic acid $250^{\circ} . R_{F} 0.70$ (solvent 1 ) and $R_{F} 0.35$ (solvent 2).

The values obtained for ( - )-robinetinidol may be compared with those reported by Roux \& Maihs (1960a), and values for the catechins, gallocatechins and their gallates with those by Vuataz, Brandenberger \& Egli (1959), Bradfield et al. (1947), Bradfield \& Penney (1948), Bradfield \& Bate-Smith (1950), Mayer \& Bauni (1957) and Roux (1957).

\section{Estimation of catechins in wattle barks}

Mature barks of black, silver, green and golden wattle were exhaustively extracted with methanol (six extractions of powdered bark of $24 \mathrm{hr}$. each at room temperature). Each extract was spotted on two-way chromatograms, with $4 \mathrm{mg}$. when finally spraying with the benzidine reagent and $6 \mathrm{mg}$. with the silver nitrate reagent. The catechins were estimated by the densitometric method as described by Roux \& Maihs $(1960 a, b)$. The variation of catechin components within species and in black $\times$ green wattle hybrids is shown in Table 2, and their concentration in the four different wattles is shown in Table 3.

\section{DISCUSSION}

The close interrelationship of $A$. mearnsii, $A$. decurrens and $A$. dealbata compared with the more distantly related $A$. pycnantha is evident from a cursory examination of their leaves. The first three may again be differentiated into the pair $A$. mearnsii and $A$. decurrens, which were at one time regarded as varietal forms of the same species $(A$. decurrens), and $A$. dealbata which, although similar, is further removed from the $A$. decurrens group. Comparison of known chemical components in the phylogenetically old and relatively unspecialized organs, e.g. heartwoods and barks of these interrelated Acacia spp., is of interest, especially in view of the extensive work by Erdtman (1959) on the 'chemical taxonomy' of coniferous plants.

The heartwoods of the four species each contain (+)-7:3':4'-trihydroxyflavan-3:4-diol, (+)-fustin, (-)-fisetinidol, fisetin and polymeric leuco-fisetinidin tannins. The concentration of these heartwood components in the wood is low and often variable (Roux \& Evelyn, 1960), apart from the existing radial gradations (Roux \& Paulus, 1961a,b). Differences in the concentration of heartwood components in different species (Table 1) are therefore not regarded as significant. The presence of identical components in the wattle heartwoods apparently confirms the general interrelationship between the four species. In the heartwood of $A$. pycnantha there are traces of minor components, e.g. gallic acid, which are not present in the $A$. dealbata-A. decurrens group.
By comparison, wattle barks have high tannin contents $(17-40 \%$ on air-dry weight), with a relatively consistent composition of catechin components and average molecular weight of tannins present in each species (Evelyn, 1956). In the barks of $A$. mearnsii and $A$. decurrens identical catechins, (-)-robinetinidol, (+)-catechin and $(+)$-gallocatechin, are present but the concentration of (+)-catechin and (+)-gallocatechin appears consistently lower $(0.45-0.65 \%$ and $0.25-0.4 \%$ respectively) in black wattles than in green wattles ( $1 \cdot 1-1.5 \%$ and $0.4-0.5 \%$ respectively). In the black $\times$ green wattle hybrids the concentrations of these catechins approximate to those in green wattle (Table 2). Black wattles growing on shale appear to have a higher concentration of $(-)$-robinetinidol in the bark than green wattles growing on the same type of soil (Table 2). In $A$. dealbata (silver wattle) bark, (-)-epicatechin and traces of (-)-epigallocatechin appear as additional components, increasing the emphasis on the 'phloroglucinol series' of catechins present. (-)-Robinetinidol is present, but in much decreased concentration (Table 3). In A. pycnantha the presence of (-)-epicatechin, (-)-epicatechin gallate, (-)-epigallocatechin and (-)-epigallocatechin gallate places even greater emphasis on the catechins of the 'phloroglucinol series' (Table 3), whereas (-)-robinetinidol, characteristic component of these Acacia barks, is present in low concentration. The isolated occurrence of gallic acid both in the bark and heartwood of $A$. pycnantha is of interest.

Considering the four species in the order of their closeness to black wattle in botanical character in the sequence $A$. mearnsii, $A$. decurrens, $A$. dealbata and $A$. pycnantha, $A$. pycnantha has the greatest number and total concentration of catechins of the 'phloroglucinol series' and also the lowest concentration of the single catechin of the 'resorcinol series' [(-)-robinetinidol] in the bark (Table 3). $A$. dealbata has a much decreased number of phloroglucinol catechins present in the bark, with the resorcinol catechin still in low concentration (Table 3). A. decurrens, closest to black wattle, has the identical composition of known catechins in the bark, but with those of the 'phloroglucinol series' present in higher concentration (Table 2). Hence the concentration and distribution of bark components in these Acacias species agree with the accepted systematics.

The isolation of $(+)$-catechin, (-)-epicatechin, (-)-epicatechin gallate, (+)-gallocatechin, (-)epigallocatechin, (-)-epigallocatechin gallate and gallic acid from the bark of $A$. pycnantha is of interest in view of the presence of the identical mixture of compounds in dried green-tea leaves (Bradfield et al. 1947; Bradfield \& Penney, 1948; Bradfield \& Bate-Smith, 1950). In golden wattle, 
however, the catechins are present as minor components associated with high-molecular-weight tannins, whereas in tea leaves they form the major phenolic components.

\section{SUMMARY}

1. The distribution of flavonoid compounds in the heartwoods and barks of four wattles (Acacia spp.) has been studied.

2. (-)-Fisetinidol, (+)-fustin, (+)-7:3':4'-trihydroxyflavan-3:4-diol, fisetin and polymeric leucofisetinidin tannins are common components to the heartwoods of $A$. mearnsii (A. mollissima) (black wattle), $A$. decurrens (green wattle), $A$. dealbata (silver wattle) and $A$. pycnantha (golden wattle).

3. The barks of $A$. mearnsii and $A$. decurrens contain (-)-robinetinidol, $(+)$-catechin and $(+)$ gallocatechin; $A$. dealbata contains these catechins together with (-)-epicatechin and (-)-epigallocatechin, and $A$. pycnantha contains these together with (-)-epicatechin, (-)-epicatechin gallate, (-)-epigallocatechin, (-)-epigallocatechin gallate and gallic acid.

4. The possible significance of the relative distribution of heartwood and bark components to the taxonomy of these, wattles is discussed.

Thanks are due to Miss M. Tindale, Royal Botanic Gardens, Sydney, Australia, for confirming the relationships between these Acacia spp.; to Mr S. P. Sherry and Professor H. Shaw, Wattle Research Institute, Pietermaritzburg, Natal, for authentic bark and heartwoods of $A$. mearnsii, $A$. decurrens and $A$. dealbata, and for black $\times$ green wattle hybrids; to the Director, Union Department of Forestry, Pretoria, for the wood and bark of A. pycnantha; and to Dr R. Child, Tea Research Institute of East Africa,
Kericho, Kenya, for dried green tea. This work was financed by the annual grant of the South African Wattle Growers' Union to the Leather Industries Research Institute.

\section{REFERENCES}

Bradfield, A. E. \& Bate-Smith, E. C. (1950). Biochim. biophys. Acta, 4, 441.

Bradfield, A. E. \& Penney, M. (1948). J. chem. Soc. p. 2249.

Bradfield, A. E., Penney, M. \& Wright, W. B. (1947). J. chem. Soc. p. 32.

Brenan, J. P. M. \& Melville, R. (1960). Kew Bull. 14, 37. Clark-Lewis, J. W. \& Roux, D. G. (1959). J. chem. Soc. p. 1402.

Erdtman, H. (1959). Proc. 4th int. Congr. Biochem., Vienna, $2,1$.

Evelyn, S. R. (1956). J. Soc. Leath. Tr. Chem. 40, 335.

Forsyth, W. G. C. (1955). Biochem. J. 60, 108.

Kalbe, H. (1954). Hoppe-Seyl. Z. 297, 19.

Keppler, H. H. (1957). J. chem. Soc. p. 2721.

Mayer, W. \& Bauni, G. (1957). Liebigs Ann. 611, 264.

Nordström, C. G. \& Swain, T. (1953). J. chem. Soc. p. 2764.

Roberts, E. A. H. \& Wood, D. J. (1951). Biochem. J. 49, 414.

Roberts, E. A. H. \& Wood, D. J. (1953). Biochem. J. 53, 332.

Roux, D. G. (1953). J. Soc. Leath. Tr. Chem. 37, 229.

Roux, D. G. (1957). Nature, Lond., 179, 158.

Roux, D. G. \& Evelyn, S. R. (1958a). Biochem. J. 69, 530.

Roux, D. G. \& Evelyn, S. R. (1958b). Biochem. J. 70, 344.

Roux, D. G. \& Evelyn, S. R. (1960). Biochem. J. 76, 17.

Roux, D. G. \& Maihs, E. A. (1958). Nature, Lond., 182, 1798.

Roux, D. G. \& Maihs, E. A. (1960a). Biochem. J. 74, 44.

Roux, D. G. \& Maihs, E. A. (1960b). J. Chromat. 4, 65.

Roux, D. G. \& Paulus, E. (1961 a). Biochem. J. 78, 120.

Roux, D. G. \& Paulus, E. (1961b). Biochem. J. 78, 785.

Vuataz, L., Brandenberger, H. \& Egli, R. H. (1959). J. Chromat. 2, 173.

Weinges, K. (1958). Liebigs Ann. 615, 203.

Biochem. J. (1961) 78, 839

\title{
A Method for the Identification of the Immediate Product of Decarboxylation Reactions
}

\author{
BY R. F. PALMER* \\ Department of Pharmacology and Therapeutics, University of Florida, Gainesville, Florida, U.S.A.
}

(Received 12 May 1960)

Under most physiological conditions the state of an enzymic decarboxylation product as bicarbonate ion, carbonic acid or carbon dioxide is deter. mined mainly by local conditions of $\mathrm{pH}$ and gas concentration. The fact that the immediate end product of a decarboxylation reaction may actually

* Present address: Department of Medicine, The Johns Hopkins Hospital, Baltimore 5, Maryland, U.S.A. be any one of the three forms would be masked by its rapid conversion into a form demanded by the buffer and gas composition of the medium. This conversion is rapid in systems where carbonic anhydrase is present. It has therefore been difficult with conventional methods to determine the immediate reaction product in carbon dioxideproducing systems. 